\title{
The Ethics of Police Body-Worn Cameras
}

Frej Klem Thomsen, Senior Researcher, Danish Institute for Human Rights

fret@humanrights.dk, Wilders Plads 8K, 1403 Copenhagen, Denmark

\begin{abstract}
Over the past decade, police departments in many countries have experimented with and increasingly adopted the use of police body-worn cameras (PBWCS). This article aims to examine the moral issues raised by the use of PBWCS, and to provide an overall assessment of the conditions under which the use of PBWCS is morally permissible. It first reviews the current evidence for the effects of using PBWCs. On the basis of this review the article sets out a teleological argument for the use of PBWCs. The final two sections of the article reviews two deontological objections to the use of PBWCs: the idea that use of PBWCs is based on or expresses disrespectful mistrust, and the idea that the use of PBWCS violates a right to privacy. The article argues that neither of these objections is persuasive, and concludes that we should conditionally accept and support the use of PBWCS.
\end{abstract}

Keywords: Surveillance; privacy; disrespect; police; body-camera; teleology; mistrust

Over the past decade, police departments in many countries have experimented with and increasingly adopted the use of police body-worn cameras (PBWCS). A PBWC is a small camera attached to a police officer's uniform while on duty, typically to the shoulder or chest, which is capable of video and audio recording events, and of transmitting or storing these recordings for later retrieval. Their use has been greeted with both enthusiasm and scepticism, with enthusiasts highlighting the fact that the recordings can provide valuable evidence both in criminal prosecution cases and in complaints against police conduct, and sceptics contending that their use may be disrespectful or violate the privacy of police officers and private citizens. However, in spite of the heated public debate about them, very little academic work has attempted to assess the ethics of police body-worn cameras. ${ }^{1}$ This article aims to remedy the situation by examining a range of moral issues potentially raised by the use of PBWCs, critically assessing which issues are of genuine moral concern, and providing an overall assessment of the conditions under which the use of PBWCs is morally permissible.

\footnotetext{
${ }^{1}$ Some treatment of the ethics of PBWCs is found in (Adams \& Mastracci, 2017; Coudert, Butin, \& Le Métayer, 2015). Adams \& Mastracci particularly discuss costs, potential humiliation, and concern for crime victims subject to filming. Coudert et al. discuss privacy of citizens and police officers, proportionality, and data security.
} 
The article proceeds as follows. In section two immediately below I review the current evidence for the effects of using PBWCs. I conclude that there is reasonably good evidence that the use PBWCs produces benefits, although the evidence is less compelling than one might have hoped and the effects of PBWC use appear to be highly dependent on the policies that govern their use. In section three, I present the teleological argument for the use of PBWCs, that is, the argument that police departments ought to use PBWCs because doing so brings about more good than bad. I note several qualifications about how to understand the goods and bads at stake and suggest that the argument should be interpreted conditionally, that is, as an argument that applies to those situations where the goods outweigh the bads and where no sufficient deontological reasons count against it. The final two sections of the article review the two arguably most obvious deontological reasons that might count against the use of PBWCs: the idea that use of PBWCs is based on or expresses mistrust in a disrespectful way, and the idea that the use of PBWCs violates a right to privacy. I argue that neither of these ideas is persuasive and conclude that we should conditionally accept and support the use of PBWCs.

\section{The use and effects of PBWCS}

The official motivation for introducing PBWCs is often three expected effects:

- that PBWCs will provide useful evidence in potentially controversial cases of interaction between police and citizens,

- that PBWCs will deter undesirable behaviour, above all the misuse of force by police, but also assaults against and harassment of police officers, unwarranted complaints, and attempts at bribery,

- that, partly as a follow-on effect of the first two effects, PBWCs will increase citizens' trust in and cooperation with police. ${ }^{2}$

Since their initial implementation, a range of studies have examined the effects of using PBWCs on these and related outcomes. ${ }^{3}$ Some initial studies showed very powerful effects. Perhaps the most famous study, a randomised controlled trial (RCT) in Rialto, California, involving 54 police officers, testing across 988 police shifts, found that use-of-force was about twice as high in control conditions as when officers employed

\footnotetext{
${ }^{2}$ See (Ariel, Farrar, \& Sutherland, 2015, p. 510; Coudert et al., 2015, p. 750; Pelfrey \& Keener, 2018, p. 2; Yokum, Ravishankar, \& Coppock, 2017, p. 2). It has also been suggested that there may be a benefit in drawing on the video material in training situations, i.e. by allowing officers to better learn from the experiences of their colleagues. (Coudert et al., 2015, p. 757; Richards, Roberts, Britton, \& Roberts, 2017) This seems plausible, though arguably of lesser importance, since police training already involves or can involve video recreations of real or fictive scenarios. I shall not discuss this potential benefit, but I note that if I have underestimated it here it strengthens the argument for the use of PBWCs.

${ }^{3}$ For good, although non-systematic reviews of the literature, see (Lum, Koper, Merola, Scherer, \& Reioux, 2015; Lum, Stoltz, Koper, \& Scherer, 2019; Maskaly, Donner, Jennings, Ariel, \& Sutherland, 2017). For a recent systematic review, see (Cubitt, Lesic, Myers, \& Corry, 2017).
} 
PBWCs, and a (statistically non-significant) ca. 90\% lower rate of complaints against officers. (Ariel et al., 2015) However, as is widely recognized, many studies have serious limitations. First, the number of methodologically solid evaluations of the effects of using PBWCs is still small and the studies often involve small sample sizes, which means that the studies both individually and collectively have limited statistical power. Second, many of the promising results found in initial studies have not been replicable in subsequent studies. (Lum et al., 2015; Maskaly et al., 2017; White, Gaub, \& Todak, 2018, pp. 2, 7-8; Yokum et al., 2017, pp. 3-4; Yokum, Ravishankar, \& Coppock, 2019) Bearing these limitations in mind, what do the studies conducted so far indicate?

Overall, there is currently reasonably good evidence for the second effect, but very little evidence for the two other effects. Thus, a number of studies have found that introducing PBWCs leads to decreases in the use of force (Jennings, Lynch, \& Fridell, 2015; White et al., 2018), and decreases in number of complaints lodged against police officers. (Ariel, 2016; Ariel, Sutherland, et al., 2016a; Grossmith et al., 2015; Hedberg, Katz, \& Choate, 2017; Jennings et al., 2015; Morgan \& Silverstone, 2017; Ready \& Young, 2015; White et al., 2018). ${ }^{4}$

An important factor, which appears to strongly affect the outcome, is the specific policy governing how PBWCs are used. When will they record, and what conditions will trigger the beginning or termination of recording? Where and for how long will the data of the recording be stored? Under which circumstances will it be accessible, and to whom? As an illustrative example, a large, multi-site RCT involving eight police departments and 2122 officers found no effects on police use of force and a surprising, small, but statistically significant increase in assaults against officers using PBWCs. (Ariel, Sutherland, Henstock, Young, Drover, Sykes, Magicks, et al., 2016) However, subsequent analysis linked differences in the results between sites to officer discretion on how to employ the PBWCs: for the three sites where compliance was high, and use of PBWCs therefore consistent, use of force decreased by $37 \%$. This effect was cancelled out by a large increase (71\%) in the use of force at those sites where officers exercised high discretion. Ariel et al. argue that this is due to the differences in induced deterrence, that is, as officer discretion over the use of PBWCs increases, deterrence decreases. Plausibly, the point of optimal deterrence is one in which officers have very limited or no discretion about whether and when to use PBWCs. (Ariel, Sutherland, Henstock, Young, \& Sosinski, 2018) The authors further speculate that the increase in assaults may also be explained by the escalating effect of turning on the camera. (Ariel, Sutherland, et al., 2016b; see also Ariel et al., 2018) That is, if police officers

\footnotetext{
${ }^{4}$ Note, however, that a range of studies have also shown null or even negative effects for arrests and charges (Ariel, 2016; Grossmith et al., 2015; Hedberg et al., 2017; Ready \& Young, 2015; Yokum et al., 2017), use of force (Ariel, 2016; Ariel, Sutherland, Henstock, Young, Drover, Sykes, Magicks, et al., 2016; Hedberg et al., 2017; Yokum et al., 2017) and complaints. (Yokum et al., 2017)
} 
only engage the camera once an interaction with a citizen has become heated and confrontational, this can be perceived by that person as a provocation, and further escalate the situation.

Policy design is further complicated by the way policies affect police officers' motivation and compliance. If officers perceive PBWCs as a technology of control, an expression of mistrust, and a risk to their career, their dissatisfaction is likely to manifest itself in overall lower work efficiency. Severe dissatisfaction can even lead to widespread sabotage. Stalcup and Cahn cite newspaper reports from US police departments where officers apparently sabotaged half of the antennas of their dashboard cameras while $80 \%$ of the audiorecording systems malfunctioned due to user error or intentional destruction, and where the introduction of PBWCs led officers to damage them, block the lens, or not turn them on. ${ }^{5}$ (Stalcup \& Hahn, 2016, p. 495) Clearly, in cases of user-resistance escalating to sabotage, we get the worst of both worlds: the economic and motivational costs of using PBWCs with none of the benefits. It is not given, however, that police officers will protest or resist the use of PBWCs. Several studies have found that police officers favour their use, including indications that officers' attitudes towards PBWCs grow more positive with experience of using them. (Morgan \& Silverstone, 2017; Pelfrey \& Keener, 2018)

The use of PBWCs is compatible with a wide range of different policies, and police departments in different countries have in fact adopted quite different policies for the use of PBWCs. (Coudert et al., 2015, pp. 750754, 758-759) Consider for ease of illustration two cartoon-style examples at opposite extremes of the policy spectrum:

\begin{abstract}
Citizens' surveillance: PBWCS are required to be active and recording throughout the entirety of every police officer's work shift. The recordings are collected and stored on a server for two weeks, whereupon they are deleted, unless they become part of an investigation. Recordings are accessible only to citizens, only upon request in the course of filing a complaint against an officer, and then only of the specific recording of the incident at stake. ${ }^{6}$
\end{abstract}

Police surveillance: PBWCs are required to be worn by every police officer throughout the entirety of their work shifts. However, the beginning and termination of recording is

\footnotetext{
${ }^{5}$ Such reports are not, pace what Stalcup and Cahn appear to imply, good evidence of the fact that police officers are resisting or will resist the use of surveillance technologies. We would want academic studies, preferably randomized controlled trials, to document such an effect. I take it, however, that they do constitute weak evidence for such resistance.

${ }^{6}$ Citizens' surveillance is, perhaps unsurprisingly, reminiscent of the ACLU's recommended policy. However, their stance on the length of data retention is oddly ambiguous: the ACLU white paper insists that retention should be 'measured in weeks not years', while the model policy includes a retention limit of six months. (American Civil Liberties Union, 2018; Stanley, 2015)
} 
entirely at the discretion of the police officer. Recordings are collected and stored on a server for as long as deemed necessary by the individual police department. Recordings are accessible only upon request by a police officer in the course of investigating or prosecuting a criminal case.

Clearly, in the light of the considerations set out above we should expect the two policies to have very different effects. Since the central argument for PBWCs is that their use will bring about goods, this also means that the ethics of PBWCs can vary substantially depending on the policy adopted. In a slogan, we are never simply evaluating the use of PBWCs, but always $a$ use, under a specific policy.

In the next section I set out the teleological argument for PBWCs, noting some important complications and qualifications, before we turn in the final sections to deontological objections against the use of PBWCs.

\section{The teleological argument for PBWCs}

The most common argument for PBWCs is teleological: we should allow police officers to employ PBWCs, and devote public resources to purchasing them and maintaining the support systems they require, because using PBWCs creates important goods, and these outweigh the bads their use brings about. ${ }^{7}$

This is a good if slightly underdeveloped argument. It is extremely plausible that any goods brought about by using PBWCs count in favour of their use, and conversely that any bads their use brings about counts against them. However, to complete an argument for the ethical permissibility of employing PBWCs we have to make an all-things-considered judgement about how all reasons, teleological and deontological, cash out. In this section I first discuss the teleological reasons at stake, and then set out a conditional teleological argument, which frames the analyses in the final sections of the article.

The first and perhaps most important benefit that motivates the use of PBWCs is their potential for reducing police use of force. As we saw above, there is some evidence that PBWCs can produce this benefit, although it is rather more mixed than one might have hoped. Improving our understanding of when and why PBWCS reduce police use of force is thus an important ongoing research issue. Another, more overlooked issue is what kind of benefit the reduction in police use of force constitutes? Much of the literature appears to assume that police use of force is simply bad, and thus that a net reduction in police use of force is always

\footnotetext{
${ }^{7}$ It is perhaps worth stressing here that my approach is not consequentialist but deliberately impartial. Teleology is the domain of practical reasons grounded in the value of outcomes. Consequentialism holds that an action is morally permissible iff it has consequences at least as good as any available alternative action, where "action" includes e.g. introducing or sustaining a policy of PBWC-use. By definition, therefore, consequentialists are concerned with teleology. However, any plausible moral theory will provide some role for teleology. Since the argument requires only this, it should be acceptable to consequentialists and deontologists alike.
} 
good, and that PBWCs are therefore desirable if they have this effect. This is too strong - we can easily imagine situations in which decreasing police use of force is all-things-considered bad. Consider:

\section{Paragons. Prior to the introduction of PBWCs, police officers in this department only ever use proportional and necessary force.}

Assuming (plausibly) that police officers ought to use force when necessary and proportional, the introduction of PBWCs in Paragons can only, therefore, reduce the use of force in a way that is morally bad.

However, use of force correlates closely with the genuine bad of harm to those individuals subject to the use of force, who will ordinarily experience the use of force as painful, stressful, and/or humiliating. Even in cases of justified use of force the correlation with harm constitutes a reason against it (this, after all, is the foundation of the necessity and proportionality requirements). In summary, a decrease in use of force is not intrinsically good but must be evaluated with respect to the harm the use of force would cause and the loss of any goods the use of force would have brought about (such as preventing harm to others).

Considerations similar to those above apply to the good of reductions in the number of complaints against police officers. When discussed as a potential benefit of using PBWCs, the assumption is often that complaints will be reduced because PBWCs deter both police behaviour that gives grounds for legitimate complaints and spurious complaints used e.g. as a means of harassing police officers. Let us grant that ordinarily either of these two effects count as goods. As above, however, the relationship between decreases in complaints and these effects may be complicated. (Ariel, Sutherland, et al., 2016a, pp. 295-296) We can imagine a situation where citizens frequently have grounds for complaint but seldom file complaints because the chance of success is miniscule. If the introduction of PBWCs gives victims access to evidence that increases the chance of filing a successful complaint, this may well lead to an increase in complaints. Furthermore, far from being lamentable, a temporary increase in complaints might be desirable in such a situation, since it will provide the police force with opportunity and incentive to adjust the behaviour of those officers giving citizens grounds for complaint. In short, the number of complaints is only a proxy for two effects of more intrinsic concern: ensuring that police officers perform their duties while respecting certain limits on their behaviour towards citizens, and that citizens do not file complaints against police officers without good reason.

Let us consider next the issue of the bads brought about by the use of PBWCs. There are two important potential bads, which I believe merit careful consideration, and four concerns that I will set aside. The former pertain to potential negative uses of the data collected and the negative reactions from public awareness of data-collection; the latter to economic costs, punishment, facial recognition technology, and data-security. 
Likely the most obvious potential bad effect of PBWC use is that the data collected by PBWCs can expose officers or civilians to humiliation, blackmail, and retaliation. As perhaps the most prominent example, humiliation can occur when the identity of an offender is revealed to her family, friends, colleagues or the general public through leakage of data. However, the problem can also apply to non-offenders, e.g. employees exposed doing something else after having called in sick, a partner in a romantic relationship meeting with their lover, or the police officer voicing critical views of their colleagues, superior or department. As the ACLU notes:

There is also the danger that the technology would be misused by police supervisors against whistleblowers or union activists - for example, by scrutinizing video records to find minor violations to use against an officer. (Stanley, 2015, p. 3)

The potential for blackmail follows on the heels of the first problem, since access to the data puts persons in a position to make demands of those vulnerable to humiliation backed up by the threat of sharing the data with relevant others. Finally, retaliation can target not only offenders themselves, but also e.g. friends or family of offenders caught on video, witnesses, victims and police officers, for a variety of reasons.

In addition to the negative effects that can follow from persons accessing the data, it is commonly held in the surveillance literature that awareness that data is being collected can deter not merely unwanted behaviour (e.g. spurious complaints), but also desirable behaviour. In the broader context of surveillance ethics, this is often referred to as the chilling effect, and recent years have seen several interesting studies that attempt to quantify it. (Marthews \& Tucker, 2017; Penney, 2016, 2017; Schauer, 1978; Stoycheff, Liu, Xu, \& Wibowo, 2019) As the Paragons-example above illustrated, we can imagine that officers will sometimes refrain from using force in situations where use of force is actually desirable, because the officer fears that use of force may be perceived as excessive and hence subject to reprimand. (Coudert et al., 2015, p. 757) There is some evidence that introducing PBWCs can lead to a decrease in arrests and an increase in traffic citations, at least one possible interpretation of which is that risk aversion leads officers to not make certain arrests that they ought to make, and to give citations when a warning might have been preferable. (Ready \& Young, 2015)

In addition to the above there are four potential concerns with the bad effects of PBWCs that I will set aside. The first, and perhaps most obvious is the expenditure of resources required to purchase PBWCs and their support systems (e.g. servers for storage), to organize training of users, to maintain equipment, and to provide administration for all of these. This expenditure is the basis of perhaps the most potent objection against a teleological argument for the use of PBWCs: that it is extremely unlikely that the resources could not have done even more good, had they been allocated to some superior purpose, such as fighting disease 
and alleviating poverty in low-income countries. The line of argument will be familiar to those who have followed the debate about effective altruism over roughly the past decade. (Gabriel, 2016; MacAskill, 2015; Singer, 2009, 2010; Unger, 1996) I believe the objection is fundamentally sound - teleology does require taking into consideration opportunity costs - but I set it aside here both because this belief is unlikely to be shared by many concerned with the permissibility of using PBWCs, and because it seems to me that it will often be possible to employ them without thereby diverting resources from a clearly more beneficial pursuit. A police chief, for example, who is considering whether to introduce PBWCs in her department will typically face a much narrower set of alternative allocations of the resources, e.g. training, performance bonuses, upgrades of equipment, renovation of facilities, community outreach, etc.

Second, if the use of PBWCs leads to more successful arrests and complaints, they will also involve additional punishment of police officers who are found guilty of some form of professional misconduct after a complaint is backed up with evidence from the PBWC, and of police officers or civilians convicted for criminal wrongdoing on the basis of such evidence. Punishment involves causing harm, and harm is a pro tanto bad. I do not believe these harms count as considerations against the use of PBWCs, however, because the good of such punishments (in the shape e.g. of beneficial deterrent effects) should outweigh the bad, and if it does not I would argue that the problem lies with miscalibration of the system of punishment rather than with the use of PBWCs.

Third, I shall assume that we are considering the use of PBWCs without facial recognition technology. This is not to deny that our choice of whether to introduce PBWCs may need to take the issue into consideration, e.g. because employing PBWCs without facial recognition technology creates a risk that it will be added later. However, since PBWCs can be used without facial recognition technology - and indeed have mostly been used in this capacity - the questions of whether it is permissible to add facial recognition technology to them, and what role if any the risk of function-creep towards that step should play, are further issues, which merit separate consideration.

Fourth, there are interesting and technically challenging issues of how to best transmit and store data so as to avoid tampering and leakages, but I shall not go into these here. (Coudert et al., 2015, p. 756) I will assume that we are considering the use of PBWCs in a context where the data is ordinarily reliably transferred and stored. ${ }^{8}$ As above, this is not because these issues do not merit attention, but because they can and should be considered separately.

\footnotetext{
${ }^{8}$ That is, I consider the potential for misuse and abuse by those persons who do have legal access to the material, but not the issue of how to technologically prevent persons, who ought not to have access, from gaining access, and the associated risks.
} 
Having considered the values at stake, let us now consider the teleological argument for the use of PBWCs:

1) Using PBWCs brings about certain goods, including deterring undesirable behaviour such as police use of excessive force and spurious complaints against police, as well as certain bads, including harms resulting from misuse and chilling effects; however, the good that employing PBWCs brings about outweighs the bad. ${ }^{9}$

2) If the good that employing PBWCs brings about outweighs the bad, then there is an overall teleological reason for police to employ PWBCs.

3) If there is an overall teleological reason for police to employ PBWCs, and no deontological reasons against police employing PBWCs, which jointly override or outweigh the teleological reason to employ PBWCs, then it is all-things-considered permissible and police ought to employ PBWCs.

C) It is all-things-considered permissible and police ought to employ PBWCs unless there are deontological reasons against using PBWCs, which jointly override or outweigh the teleological reason to employ PBWCs.

In spite of its apparent simplicity, I believe the argument requires several comments and qualifications.

First, the conclusion of the argument is conditional since this seems to me the easiest way to structure the discussion of the moral permissibility of PBWCs, and because I do not wish to rule out at the outset the possibility that a relevant deontological reason exists. If we wanted, we could easily create an unconditional argument by adding the premise that there is no relevant deontological reason and revising the conclusion accordingly. It makes no difference in the following whether we take the purpose of reviewing deontological objections to be assessing the condition or a hypothetical fourth premise.

Second, deontological reasons can directly outweigh the overall teleological reason, or they can override it. That is, a deontological reason might be thought to shift the balance of reasons against the permissibility of using PBWCs (outweighing), or to determine the all-things-considered permissibility of using PBWCs irrespective of the weight of the teleological reason (overriding). My phrasing is meant to capture both these possibilities, when they result in the balance of reasons shifting against the permissibility of using PBWCs.

Third, premises 2 and 3 are applications of very plausible general claims in moral philosophy. I can think of no reason why anyone would deny them, and I shall assume that they are true.

\footnotetext{
${ }^{9}$ Recall that the goods and bads here are more contingent than is sometimes assumed. I have qualified them so as to indicate this, e.g. by focusing on police use of excessive force, but this should be construed as a short-hand for rather than an alternative to the more fundamental point: that such instrumental goods must ultimately be assessed in the light of a principled value theory.
} 
Fourth, however, our review of the evidence and qualifications for premise 1 above illustrated that its veracity is not equally clear. Nonetheless, I will assume in the following that it is true, or more precisely, that we are considering the use of PBWCs in those situations where it is true. Partly this is because it seems to me that premise 1 being true is an uncontroversially necessary condition for permissible use of PBWCs. Even if one thinks that there can be situations, where an action is morally permissible although it does more bad than good, I cannot imagine anyone would think that this is the case with respect to the use of PBWCs. Thus, the issue of the permissibility of the use of PBWCs only genuinely arises for those situations where premise 1 holds, so that it seems reasonable to focus our ethical analysis on that subset. At the same time, the studies conducted so far seem to me adequate grounds for cautious optimism that the premise will actually be true in liberal societies given a suitable policy structure. Designing that policy structure for a particular context and evaluating whether the premise then holds is likely to be both a challenging and interesting task, but it is one that moral philosophers are better off leaving to scholars of disciplines more suited to pursuing its solution.

Given this assumption, the argument is sound. The obvious next question is what the status of the condition in the conclusion is. That is, are there deontological reasons against using PBWCs that jointly override or outweigh the teleological reason in favour? It is to this question that the remaining two sections of this article are devoted. Specifically, I will review arguments to the effect that using PBWCs is mistrustful in a morally problematic way, and that the use of PBWCs can violate a moral right to privacy.

\section{Is employing PBWCs a morally problematic form of mistrust?}

One argument against the use of PBWCs, which is sometimes offered by police spokespersons, is that PBWCs are bad and should not be employed because their use constitutes a morally problematic form of mistrust of police officers. In reviewing this objection, we must be careful to separate the claim at stake from a closely related claim. It is obvious that police officers may feel that the use of PBWCs is a form of mistrust towards them, and that this may have various negative effects, e.g. for their motivation. Such negative effects, however, are properly part of the weighing of goods and bads at the core of the teleological argument for PBWCs. If we are to avoid simply restating an element of that argument, then the claim at stake here must be different. The objection, therefore, is rather the idea that independently of any negative effects, the fact that introducing PBWCs is a form of mistrust makes their use morally problematic.

There are two parts to this claim that must be considered separately: First, in what sense is using PBWCs mistrustful? And second, why is this form of mistrust morally problematic? We must be careful to consider these separately, but also to not equivocate. Whatever answer we give to the first question must be imported when considering the second. It will not suffice, for an objection against PBWCs, to establish that the use of 
PBWCs instantiates mistrust in one sense, only to argue that mistrust in a different sense can be morally problematic.

In what sense, then, can the use of PBWCs be said to be mistrustful? On the one hand, such use might be held to express mistrust, that is, to imply or publicly signal that police officers are not trustworthy. On the other hand, the use of PBWCs might be held to be motivated by mistrust, that is, to be employed by authorities whose decision to do so rests at least in part on the belief that police officers cannot be trusted. It is also possible, of course, to hold that the use of PBWCs both expresses and is motivated by mistrust.

Mistrust in either of these senses is related to a belief, which is either implied by or motivates the action. An obvious question therefore is how more precisely we ought to understand the content of this belief. Crucially, mistrust could conceivably cover a range of claims of varying strength. For illustration, consider an extremist version:

Paranoid mistrust: all police officers will violate their professional obligations at every opportunity unless deterred by the constant monitoring of an authority capable of imposing sanctions.

Presumably, nobody will seriously suggest that any mistrust at stake in the use of PBWCs need be of this paranoid variety. It is exceedingly implausible that proponents of PBWCs hold this belief, or that employing PBWCs can reasonably be interpreted as implying it. Consider for comparison a minimalist version:

Bare hypothetical mistrust: there is at least a very small chance that at least one police officer might at one point violate their professional obligations and that monitoring by an authority capable of imposing sanctions could deter this.

This minimalist claim is overwhelmingly likely to be true, and it is also very plausible both that proponents of PBWCs hold and are motivated by it, or a stronger comparable belief, and that the use of PBWCs can be interpreted as implying it, or some stronger comparable belief. Between the extremist and minimalist versions there is, of course, a whole spectrum of possible beliefs, and it is not, I think, clear exactly where on this spectrum the actual claims expressed or held by proponents of PBWCs might lie.

Now let us consider the second issue, of what might be morally problematic about mistrust. The most obvious possibility, it seems to me, is that an expression of or motivation by mistrust is morally problematic because it is disrespectful, in the sense that it expresses or rests on a false or unjustified belief, which ascribes a 
morally worse status to the agent than she actually has or than evidence suggests she has. ${ }^{10}$ Such accounts of disrespect are reasonably well developed in other contexts. (Darwall, 1977, 2006; Eidelson, 2015; Frankfurt, 1997; Hellman, 2008) Note that all features of this description are necessary. It is not obvious that I am disrespectful if I attribute to some person a morally undesirable characteristic, which she actually possesses and for which I have sufficient evidence. Labelling the misogynistic workplace-tyrant a chauvinist or calling the pathologically lying career politician a swindler accords to that person the respect that she merits, or, which is perhaps to say the same thing, is disrespectful only in a morally unproblematic way. ${ }^{11}$ Similarly, it is not clear that I am disrespectful to a person if I overestimate the extent to which she possesses some morally desirable characteristic. Attributing greater kindness to my child or diligence to my colleague than they actually exhibit is intuitively not problematic in the same way. There may be problems with such idolising, particularly I think the implicit demands idolising can make on those idolised, but if so these are best considered separately. Finally, note that disrespect presumably comes in degrees and that there is presumably a more or less direct correlation between the degree of disrespect and the degree of moral badness. If disrespect is morally bad, then it is morally worse because more disrespectful to mistakenly label an average person a moral monster than it is to mistakenly label the same person a moral petty villain.

The disrespectful mistrust challenge to PBWCs might then (loosely formulated) be the following:

1) The use of PBWCs implies or is based on a belief that police officers are likely to violate their professional obligations.

2) This is disrespectful because it attributes to police officers a worse professional character than they actually possess or evidence actually warrants.

3) Disrespect of this form and extent is morally bad, such that the reason to avoid it either outweighs or overrides the teleological reason for the use of PBWCs.

Jointly, the premises entail that the condition of teleological argument's conclusion is satisfied - there is in fact a deontological reason, which makes the use PBWCs impermissible in spite of the teleological reason in favour. If the premises are true, then we therefore cannot use the teleological argument to defend the permissibility of using PBWCs. There are, however, at least three ways to defend the use of PBWCs against the disrespectful mistrust challenge, focused on each of the premises in turn.

\footnotetext{
${ }^{10}$ It is not entirely clear whether we best conceive of disrespectful mistrust as ascribing a false character to a person or ascribing a character that evidence does not support (or, perhaps, both). Since either possibility seems to me an option the proponent of the objection might want to pursue, I shall consider both interpretations.

${ }^{11}$ Friends of disrespect accounts are not, it seems to me, always careful to distinguish between purely descriptive senses of disrespect, in which we might say that we disrespect the chauvinist or the swindler, and evaluative senses of disrespect, in which disrespecting other persons is something which we ought, all else equal, to avoid.
} 
First, one can argue that, pace premise three, the badness of the disrespect at stake does not ground a reason that outweighs or overrides the teleological reason for the use of PBWCs. This is the case, clearly, if disrespect is not morally bad at all. Although I believe that argument can be made quite persuasively I will not pursue it here since it seems to me that there are easier ways of defending the teleological argument for PBWCs against the challenge. ${ }^{12} \mathrm{~A}$ simpler way to support the first line of defence builds on the observation that, as we have noted, it seems clear disrespect is morally worse the greater the disrespect. Thus, even if the use of PBWCs is mistrustful, and this mistrust is disrespectful, and disrespect is morally bad, it does not follow that the disrespect at stake is sufficiently bad that it outweighs or overrides the teleological reason in favour of using PBWCs. It would rather appear to be an open question whether the disrespect at stake in any concrete situation is sufficiently great to make the use of PBWCs impermissible, and an open question to which, it seems to me, the opponent of PBWCs will find it difficult to provide a satisfactory answer. ${ }^{13}$

As a second defence, one can argue that, pace premise one, the use of PBWCs need not imply or be based on any beliefs, mistaken or otherwise, about the professional character of police officers. A first approach at this line of defence raises the question of how we are supposed to determine whether a policy or practice expresses or is based on a certain belief? We might of course be in the fortunate situation that the agents responsible for the policy or practice are explicit about the role of the belief: 'Introducing PBWCs will put a stop once and for all to the many violations perpetrated by police officers!' But excluding this scenario, how do we decide what the policy or practice expresses and/or is based on? Proponents of PBWCs might hold that their use expresses or is based on e.g. concern for police officers (since they provide evidence that can protect against false accusation of police harassment) and the public (since they can provide evidence that can ensure convictions). In many situations it is likely that there will be ample room for reasonable disagreement about what the use of PBWCs expresses, and what beliefs their use is motivated by.

A second approach to the second line of defence can point out that a policy or practice might express and/or be based on a number of beliefs. Does it matter which role the particular belief plays in the larger scheme of things? Is it, for example, reasonable to say that the entire policy or practice becomes disrespectful, if the

\footnotetext{
${ }^{12}$ For strong challenges to disrespect accounts of wrongful action see (Lippert-Rasmussen, 2013; Pettit, 1989)

${ }^{13}$ Is this requirement dialectically unfair, in placing the burden of proof on those presenting the objection? That is, might a person presenting the objection counter that it is up to the proponent of the use of PBWCs either to show that the reason in their favour is strong enough that the objection fails, to show that the objection is weak enough that it fails, or perhaps both? Or more mildly, that requiring that they lift this burden sets before them an impossible task, and is therefore unreasonable? I do not think so. Although there are no hard and fast principles for the dialectics of burdenshifting, it does not seem to me unreasonable to ask that the participant who offers an objection be the one to provide arguments establishing its strength. And the task does not seem to me impossible, so long as we do not impose unreasonable requirements of accuracy and certainty. The point is only that even by the standards and practices common to applied ethics, the task while necessary looks difficult.
} 


\section{Ethics of Police Body-Worn Cameras}

particular belief that is supposed to make it so plays only a very minor part, and the more important beliefs expressed and held are morally unobjectionable or perhaps even laudable? In at least some situations it might sound more plausible to say that the particular belief is morally bad, but that this is insufficient to render the policy or practice as a whole morally bad because disrespectful.

Perhaps there are counters to these two approaches to the second line of defence. If so there remains the third, and to my mind, strongest line of defence: that even if the use of PBWCs expresses or is based on mistrust, pace premise two this mistrust need not be disrespectful, because such a belief is not necessarily mistaken or unjustified. Recall two facts we previously observed, that there is a range of mistrustful beliefs, the weakest of which are fairly innocuous, and that even a negative belief, such as mistrust, is only disrespectful in the sense that is morally bad, if it is false or unjustified. Thus, it is only if the use of PBWCs expresses or is based on a level of mistrust that is greater than the situation or evidence warrants, that this mistrust can be held to be disrespectful.

How much mistrust do actual police officers warrant? We can imagine situations in which any substantial level of mistrust is unwarranted, but these belong in the realm of thought experiments. As criminological studies have amply shown, real-life police departments are places where mistakes are made. (E. Armacost, 2004; Eitle, D’Alessio, \& Stolzenberg, 2014; Harris, 2009; Kane \& White, 2009) There will be variations from one context to another, obviously. Some police departments probably warrant a great deal of mistrust, since a combination of institutional and situational factors make them places in which police violations of professional obligations are endemic. Other police departments probably warrant fairly limited mistrust, since they are places where such violations occur only sporadically, and primarily because of a few individual police officers - the "bad apples". The underlying point, however, is that it seems entirely appropriate to express or hold some degree of mistrust towards any police department.

Does the use of PBWCs express or rest on a greater degree of mistrust than this? It seems to me very difficult to establish with any certainty that it does. The proponent of the disrespectful mistrust challenge must clear two very difficult hurdles to substantiate the charge. First, she must determine with some reasonable degree of accuracy what the appropriate level of mistrust is. Second, she must show not only that we can reasonably interpret the use of PBWCS as expressing or resting on mistrust, but that the level of this mistrust is greater than that which she has established is warranted in the situation. To my knowledge no one has yet attempted to lift this argumentative burden, and I do not know how a proponent attempting to do so might proceed. At best this leaves the mistrustful disrespect challenge severely underdeveloped, and the proponent with a great deal of work ahead of her. At worst, the difficulties involved suggest that we ought to discard the challenge entirely. 


\section{Does the use of PBWCs violate a moral right to privacy?}

Let us consider finally perhaps the most commonly cited concern with the use of PBWCs: their effect on the privacy of officers and citizens. (e.g. Ariel et al., 2015, p. 529) It is important to make a vital clarification to this objection to PBWCs at the outset: It seems obvious that police officers can act in ways that problematically decrease persons' privacy, but this does not by itself ground a challenge to PBWCs. A police officer who sneaks into a civilian residence to observe a person in the shower is intuitively and uncontroversially doing something morally bad, and privacy seems to be a prominent part of the explanation of why this is bad. What we are considering, however, is the difference that the use of PBWCs makes. Reviewing situations where police officers violate privacy with or without PBWCs will not be informative. Therefore, I shall assume that we are considering the use of PBWCs only in those situations, whatever more specifically these might be, where police officers can ordinarily perform their duties without impermissibly infringing on personal privacy, and that the objection is that introducing PBWCs in these situations somehow creates a problem of privacy.

This restriction does not steal the critic's thunder, because even authors sympathetic to the use of PBWCs clearly often believe that their ordinary use involves loss of privacy and that this counts against their use. Thus, Coudert et al. argue that constant surveillance of police officers during their work is 'an extreme measure that can only be justified under specific circumstances of greater risks for police officers or citizens. A trade-off must be found.' (Coudert et al., 2015, p. 757) This view is in tension with the apparent desirability of minimising officer discretion with respect to recording, which we noted while reviewing the effect of policies. For the purposes of producing beneficial deterrence, the ideal might be for PBWCs to record continuously throughout every shift of every active duty police officer, but for the purposes of preserving privacy, recording should apparently be kept to a minimum. Privacy and goods - how should we balance the two?

In spite of how strong a position they adopt on privacy as a constraint on the use of PBWCs, Coudert et al. do not offer any arguments for it. ${ }^{14}$ Their claims do not strike me as intuitive, and even if they were we would still want to know what grounds them. Arguably, the most promising idea is that privacy loss can make the use of PBWCs impermissible when and because it violates a moral right to privacy. To assess an argument that the use of PBWCs will violate a right to privacy, however, we need to know what such a right consists in,

\footnotetext{
${ }^{14}$ In fact, oddly, Coudert et al. also claim that: 'The first interference, into police officers' privacy, can be justified by the need to protect citizens from a disproportionate use of force. [...] The second interference, into citizens' privacy, can be justified by the higher social need to ensure the accountability of police forces or the more specific need to protect police forces' physical integrity.' (Coudert et al., 2015, p. 756) It is not clear to me how they combine the two positions.
} 
what moral weight to ascribe it, and whether it would apply to the situation at hand, that is, to the use of PBWCS.

Rights fundamentally concern moral claims, whether it is a claim to the permissibility of $\Phi^{\prime}$ ing, a claim to the impermissibility of others preventing me from $\Phi^{\prime}$ ing, a claim to the impermissibility of others $\Phi^{\prime}$ ing, or a claim to the permissibility of me preventing others from $\Phi^{\prime}$ ing. This is, obviously, the conventional Hohfeldian analysis. (Hohfeld, 1913) In the context of a right to privacy, we are primarily concerned, I believe, with a claim to the impermissibility of others performing certain actions that would reduce a person's privacy, so I shall refer mostly to that in the following, but the points extend easily to any other component claims of a right to privacy.

I think we ought furthermore to distinguish two possible versions of a right to privacy that differ in terms of what nature they take the claim to have. On the one hand, we might take a right to be the ground of a moral claim, in which case you have a right to a person not reducing your privacy iff there is a particularly strong deontological reason for its being impermissible that they reduce your privacy. On the other hand, we might take a right to be a moral claim as the outcome of weighing moral factors, in which case you have a right to a person not reducing your privacy iff it is all-things-considered impermissible for them to reduce your privacy. ${ }^{15}$ Since, however, the issue at stake is exactly the all-things-considered permissibility of privacyreducing PBWC-use, a right to privacy in the second sense cannot be the basis of a challenge, so I shall assume that we are dealing with a right in the former.

Attempts at developing and defending a right to privacy along such lines have been made by a fair number of scholars. (e.g. Alfino \& Mayes, 2003; Corlett, 2002; Davis, 2009; Griffin, 2007; Macnish, 2016; Marmor, 2015; McCloskey, 1980; Rickless, 2007; Wall, 2011) One approach might be to claim that there is a nonderivative deontological reason against depriving a person of privacy, which is to say that decreasing a person's privacy is (in at least some cases) wrong just because it is wrong. This approach faces extraordinarily powerful objections however, including Thomson's famous argument that it overlaps with rights that can more plausibly explain the wrongness of acts, and the strongly counterintuitive implications it would have in certain common situations. (Doyle, 2009; Ryberg, 2007; Thomson, 1975) Furthermore, defenders of the right to privacy in the literature all but universally take the position that privacy is instrumental to more fundamental moral factors, such as the importance of being able to pursue autonomous projects or maintain

\footnotetext{
${ }^{15}$ John Oberdiek nicely draws out this distinction, albeit in a slightly different context and for different reasons. (Oberdiek, 2008)
} 
valuable social relations. ${ }^{16}$ Thus, I will further assume that the right to privacy is grounded on such a more fundamental deontological reason.

The right to privacy challenge to PBWCs might then (loosely formulated) be the following:

1) The use of PBWCs decreases the privacy of police officers and civilians subject to recording.

2) There is a deontological reason to not decrease privacy such that this reason either outweighs or overrides the teleological reason for the use of PBWCs.

The right to privacy objection to PBWCs immediately faces a dilemma. On the one hand it must avoid consequentialisation, that is, ending up pointing merely to yet another value that must be included in the teleological weighing. (Brown, 2011) On the other hand, it must claim that the use of PBWCs actually reduces privacy in a way that relevantly affects the interests at stake. Jointly, these two constitute a dilemma, I will argue, since it is not apparent that the objection can avoid the former while plausibly claiming the latter.

The challenge of consequentialisation is this: for any alleged moral factor which depends on privacy, we can attempt to explain the reasons in favour of protecting privacy in terms of its being instrumentally valuable in promoting or protecting the intrinsic value of that moral factor. If for example social relations are valuable, intrinsically or instrumentally (e.g. to human flourishing or well-being), and privacy promotes or protects social relations, then we can explain the moral significance of privacy in strictly teleological terms. As with the mistrust objection above, these are concerns with which we have already engaged: the balancing of the good and bad of employing PBWCs. To avoid consequentialisation, the objection at stake must be that losing privacy can make the use of PBWCs impermissible for reasons above and beyond the disvalue of privacy loss.

\footnotetext{
${ }^{16}$ Thus, Angelo Corlett believes that 'a certain level of privacy, and a right to it being respected, is necessary for one to even attempt to become an authentic (project-pursuing) self in society'. (Corlett, 2002, p. 336) Andrei Marmor develops a related argument in somewhat greater detail, when he argues that the fundamental interest protected by a right to privacy is the interest in the capacity to shape one's social relations with others. As Marmor argues, a world entirely without privacy would be one in which we would at once be unable to differentiate between how friends, colleagues and romantic partners knew us, unable to foster certain relationships by bestowing intimacy, and unable to think, feel or do certain things without fear of how others might react. (Marmor, 2015, pp. 8-11) Similar arguments have been advanced by a number of thinkers, including (Nagel, 1998; Rachels, 1975). Meanwhile, Steven Davis claims that: 'It is the range and importance of the objects of the desires, the state of affairs, which are realized if the desires are fulfilled, to which privacy is contingently related that give moral grounding and thus, moral value to privacy. Since we place great moral value on respect, dignity, love, etc., we should place moral value on those states and activities that promote them, even if their promoting them is not necessary, but contingent on the structure and attitudes of different societies. [...] Given the importance of the values that privacy promotes, some of which themselves are moral rights, respect, and dignity, for example, it would follow that privacy is a right in those societies in which it plays an important or central role in fostering these important values. Hence, the justification for taking privacy to be a right is instrumental; it contingently fosters other values that we take to be of central importance in giving a moral value to our lives.' (Davis, 2009, p. 466)
} 
The most obvious way of framing the right to privacy challenge that meets this requirement is to adopt a threshold view, something like the following: we have strong deontological reasons to protect some moral factor, such as autonomy. This moral factor requires a certain amount of privacy. The reasons, being deontological, are not grounded in the moral value of autonomy, and privacy is not instrumentally valuable above or below this threshold. We simply have instrumental reasons to protect the specific privacy needed to protect the moral factor. Apart from avoiding the challenge of consequentialisation, this threshold view, or something very like it, is in fact, it seems to me, the line of argument pursued by most proponents of a right to privacy.

The trouble for the threshold view is that it seems forced to claim either too little to condemn PBWCs or too much to be plausible. After all, the claim here is a dramatic one: if we do not preserve the required minimum of privacy, then some vital aspect of our human lives, such as our ability to form meaningful social relations, or to develop autonomous projects, will be damaged. And yet, it does not appear to be the case that the introduction of PBWCs has had anything like this effect in practice. If, for example, the introduction of PBWCs in Metropolitan London has damaged or destroyed the social relations or autonomy of Londoners, then Londoners seem to have failed to notice.

Responding to this apparent lack of impact can leave the proponents of the right to privacy challenge claiming too little. We can imagine proponents who accept that the apparent lack of impact show the damage to social relations or autonomy to be very small. If, however, using PBWCs has deprived persons of privacy beyond the threshold required for some moral factor, and the damage to that moral factor from crossing the threshold is so small as to be unnoticeable, then it seems unlikely that the reason to preserve privacy in order to protect that moral factor can shift the balance of reasons against the teleological reasons for the use of PBWCs. ${ }^{17}$

Responding to the apparent lack of impact can also leave proponents of the right to privacy challenge claiming too much. If they maintain that loss of social relations or autonomy would be non-trivial, then the lack of apparent impact must be explained in one of three ways. It might be a) because there are no such thresholds, $b$ ) because the use of PBWCs does not reduce privacy beyond a threshold, or c) because

\footnotetext{
${ }^{17}$ The same consideration would apply to those willing or even eager to accept the consequentialisation of the privacy challenge. That is, a hypothetical proponent of a teleological argument for privacy, who held that their concern with the use of PBWCs is grounded in the impact that reduced privacy will have on autonomy, social relations, etc., but also that the reasons at stake are teleological because social relations or autonomy are intrinsically valuable, and who do not therefore need to rely on a threshold. Such a proponent might say that it is true that these concerns should be factored into the teleological equation, but that my failure to actually do so has led me to underestimate the badness of employing PBWCs. Here again, the response would be that the apparent lack of impact suggests that any disvalue grounded in loss of social relations or autonomy is trivial and thus unlikely to outweigh the teleological reasons in favour of using PBWCs.
} 
confounding factors have made persons overlook what they have lost. The unenviable task for proponents of the objection that use of PBWCs violates a moral right to privacy by non-trivially damaging an important moral factor thus seems to be to render more plausible the third than the first or the second of these explanations. Until a persuasive argument to that effect is provided, it seems to me that we can reasonably conclude that it is at the very least unlikely that the use of PBWCs violates a right to privacy.

\section{Conclusion}

Over the course of this article, I have first reviewed the empirical evidence on the effects of using PBWCs, and suggested that it gives grounds for cautious optimism, that with the right policy structure, using PBWCs can bring about substantial goods in the shape of a reduction of police misconduct and spurious complaints, which outweigh the risks the data collection creates and any chilling effects. On this basis, I set out the teleological argument for PBWCs, suggesting that at least in the situations in which the good that using PBWCs brings about outweighs the bad, it is permissible to use them, unless there are deontological reasons that count against their use, and these reasons are sufficient to make their use impermissible despite the overall teleological reason in their favour. This led in turn to a critical review of two potential deontological objections to the use of PBWCs: the disrespectful mistrust challenge and the right to privacy challenge. Against the first, I argued that it is unclear that the use of PBWCs need involve mistrust, that the disrespect is sufficient to make their use impermissible, and that it is up to the critic to lift the heavy argumentative burden of showing that any mistrust at stake is great enough to be disrespectful. Against the second, I argued that a suitable right to privacy must be grounded in a more fundamental deontological concern, such as autonomy or intimate relations, for which a certain minimum of privacy is necessary, but that it is implausible that the use of PBWCs has in practice reduced privacy beyond this threshold without those affected noticing. The time has come to conclude.

I have made a number of important assumptions to support the argument in favour of using PBWCs, which merit repeating at this point, since they illustrate the contingent nature of the claim that the use of PBWCs is permissible. First, I set aside the use of facial-recognition technology and the challenge of data security. The argument depends either on PBWCs being used without facial-recognition technology, or on such technology being independently shown to be permissible, and on there being appropriate levels of data security. I also set aside the issue of opportunity costs - if there turn out to be more worthwhile uses of the resources society could devote to introducing or using PBWCs, then the argument for them falters. Finally, I have reviewed what seem to me the two strongest deontological challenges to the use of PBWCs and shown why neither is capable of prohibiting their use. But I cannot, of course, rule out the possibility of either of these challenges being revised and persuasively presented, or of an alternative challenge being presented, 
which I have overlooked. The argument stands only so long as these possibilities are not realized. Bearing all these qualifications in mind, my conclusion remains that the use of PBWCs appears to be permissible.

There remain plenty of legitimate concerns with the employment of PBWCs, but they are concerns that are amenable to solution rather than concerns that fundamentally challenge the permissibility of using PBWCs. Thus, there may be cases where the use of PBWCs is undesirable, either because the institutional climate does not allow the appropriate policies to be implemented, or because external conditions are unfavourable. But this is not, so far as evidence allows us to see, the case in the liberal, wealthy societies where PBWCs have so far been most widely introduced, and where debate about their use has been most focused. There may also be cases where PBWCs are actually introduced with inappropriate policy-structures, and where it is therefore true that it would have been better had they not been introduced. But this does not mean that PBWCs cannot be used with the appropriate policy structure, nor that the solution in those countries is removing PBWCs rather than fixing policies.

Debate about the use of PBWCs tends, like so many debates about important new technologies, to splinter participants into opposing camps who are either strongly in favour or vehemently opposed. Throughout this article, I have attempted to show that the issue is complex, and that while there is a good argument in favour of using PBWCs, it is both narrower in the scope of its conclusion and more dependent in its premises than proponents might have hoped. Thus, to both critics and supporters of PBWCs I say that the answer to the question of whether the use of PBWCs is morally permissible in a particular case must be a resounding "Probably, but it all depends..."

\section{References}

Adams, I., \& Mastracci, S. (2017). Visibility is a Trap: The Ethics of Police Body-Worn Cameras and Control. Administrative Theory \& Praxis, 39(4), 313-328. doi:10.1080/10841806.2017.1381482

Alfino, M., \& Mayes, G. R. (2003). Reconstructing the Right to Privacy. Social Theory \& Practice, 29(1), 1-18.

American Civil Liberties Union. (2018). A Model Act for Regulating the Use of Body Worn Cameras by Law Enforcement (version 2.1). Retrieved from https://www.aclu.org/other/model-act-regulating-usewearable-body-cameras-law-enforcement

Ariel, B. (2016). Police Body Cameras in Large Police Departments. Journal of Criminal Law \& Criminology, 106(4), 729-768.

Ariel, B., Farrar, W. A., \& Sutherland, A. (2015). The Effect of Police Body-Worn Cameras on Use of Force and Citizens' Complaints Against the Police: A Randomized Controlled Trial. Journal of Quantitative Criminology, 31(3), 509-535. doi:10.1007/s10940-014-9236-3

Ariel, B., Sutherland, A., Henstock, D., Young, J., Drover, P., Sykes, J., . . Henderson, R. (2016). Wearing body cameras increases assaults against officers and does not reduce police use of force: Results from a global multi-site experiment (Vol. 13).

Ariel, B., Sutherland, A., Henstock, D., Young, J., Drover, P., Sykes, J., .. . Henderson, R. (2016a). “Contagious Accountability": A Global Multisite Randomized Controlled Trial on the Effect of Police Body-Worn 
Cameras on Citizens' Complaints Against the Police. Criminal Justice and Behavior, 44(2), 293-316. doi:10.1177/0093854816668218

Ariel, B., Sutherland, A., Henstock, D., Young, J., Drover, P., Sykes, J., . . Henderson, R. (2016b). Report: increases in police use of force in the presence of body-worn cameras are driven by officer discretion: a protocol-based subgroup analysis of ten randomized experiments. Journal of Experimental Criminology, 12(3), 453-463.

Ariel, B., Sutherland, A., Henstock, D., Young, J., \& Sosinski, G. (2018). The Deterrence Spectrum: Explaining Why Police Body-Worn Cameras 'Work' or 'Backfire' in Aggressive Police-Public Encounters. Policing: A Journal of Policy and Practice, 12(1), 6-26. doi:10.1093/police/paw051

Brown, C. (2011). Consequentialise This. Ethics, 121(4), 749-771.

Corlett, J. A. (2002). The nature and value of the moral right to privacy. Public Affairs Quarterly, 16(4), 329350.

Coudert, F., Butin, D., \& Le Métayer, D. (2015). Body-worn cameras for police accountability: Opportunities and risks. Computer Law \& Security Review, 31(6), 749-762. doi:http://dx.doi.org/10.1016/j.clsr.2015.09.002

Cubitt, T. I., Lesic, R., Myers, G. L., \& Corry, R. (2017). Body-worn video: A systematic review of literature. 50(3), 379-396. doi:10.1177/0004865816638909

Darwall, S. L. (1977). Two Kinds of Respect. Ethics, 88(1), 36-49.

Darwall, S. L. (2006). The Second-person Standpoint: Morality, Respect, and Accountability: Harvard University Press.

Davis, S. (2009). Is there a right to privacy? Pacific Philosophical Quarterly, 90(4), 450-475.

Doyle, T. (2009). Privacy and perfect voyeurism. Ethics and Information Technology, 11(3), 181-189. doi:10.1007/s10676-009-9195-9

E. Armacost, B. (2004). Organizational Culture and Police Misconduct. George Washington University Law Review, 72(3), 453-546. doi:10.2139/ssrn.412620

Eidelson, B. (2015). Discrimination and Disrespect. Oxford: Oxford University Press.

Eitle, D., D'Alessio, S. J., \& Stolzenberg, L. (2014). The Effect of Organizational and Environmental Factors on Police Misconduct. Police Quarterly, 17(2), 103-126. doi:10.1177/1098611114522042

Frankfurt, H. (1997). Equality and Respect. Social Research, 64(1), 3-15.

Gabriel, I. (2016). Effective Altruism and its Critics. Journal of Applied Philosophy, 34(4), 457-473.

Griffin, J. (2007). The Human Right to Privacy. San Diego Law Review, 44(4), 697-721.

Grossmith, L., Owens, C., Finn, W., Mann, D., Davies, T., \& Baika, L. (2015). Police, Camera, Evidence: London's cluster randomised controlled trial of Body Worn Video. Retrieved from London:

Harris, C. J. (2009). Police Use of Improper Force: A Systematic Review of the Evidence. Victims \& Offenders, 4(1), 25-41. doi:10.1080/15564880701568470

Hedberg, E. C., Katz, C. M., \& Choate, D. E. (2017). Body-Worn Cameras and Citizen Interactions with Police Officers: Estimating Plausible Effects Given Varying Compliance Levels. Justice Quarterly, 34(4), 627651. doi:10.1080/07418825.2016.1198825

Hellman, D. (2008). When Is Discrimination Wrong? Cambridge: Harvard University Press.

Hohfeld, W. N. (1913). Some Fundamental Legal Conceptions as Applied in Judicial Reasoning. The Yale Law Journal, 23(1), 16-59. doi:10.2307/785533

Jennings, W. G., Lynch, M. D., \& Fridell, L. A. (2015). Evaluating the impact of police officer body-worn cameras (BWCs) on response-to-resistance and serious external complaints: Evidence from the Orlando police department (OPD) experience utilizing a randomized controlled experiment. Journal of Criminal Justice, 43(6), 480-486. doi:http://dx.doi.org/10.1016/j.jcrimjus.2015.10.003

Kane, R. J., \& White, M. D. (2009). Bad cops. Criminology \& Public Policy, 8(4), 737-769. doi:10.1111/j.17459133.2009.00591.x

Lippert-Rasmussen, K. (2013). Born Free and Equal? A Philosophical Inquiry Into the Nature of Discrimination. Oxford: Oxford University Press. 
Lum, C., Koper, C., Merola, L., Scherer, A., \& Reioux, A. (2015). Existing and Ongoing Body Worn Camera Research: Knowledge gaps and opportunities. Retrieved from Fairfax, VA:

Lum, C., Stoltz, M., Koper, C. S., \& Scherer, J. A. (2019). Research on body-worn cameras. 18(1), 93-118. doi:10.1111/1745-9133.12412

MacAskill, W. (2015). Doing good better : how effective altruism can help you make a difference: Gotham Books.

Macnish, K. (2016). Government Surveillance and Why Defining Privacy Matters in a Post-Snowden World. Journal of Applied Philosophy, 33(3).

Marmor, A. (2015). What Is the Right to Privacy? Philosophy and Public Affairs, 43(1), 3-26.

Marthews, A., \& Tucker, C. E. (2017). Government surveillance and internet search behavior. SSRN Electronic Journal.

Maskaly, J., Donner, C., Jennings, W. G., Ariel, B., \& Sutherland, A. (2017). The effects of body-worn cameras (BWCs) on police and citizen outcomes: A state-of-the-art review. Policing: An International Journal, 40(4), 672-688. doi:10.1108/PIJPSM-03-2017-0032

McCloskey, H. J. (1980). Privacy and the Right to Privacy. Philosophy, 55(211), 17 - 38.

Morgan, J., \& Silverstone, D. (2017). Trialling Body-Worn Video Cameras for City of London Police: Officer Perceptions and Justice Outcomes. Retrieved from London:

Nagel, T. (1998). Concealment and Exposure. Philosophy and Public Affairs, 27(1), 3-30.

Oberdiek, J. (2008). Specifying Rights Out of Necessity. Oxford Journal of Legal Studies, 28(1), 127-146. doi:10.1093/ojls/gqm028

Pelfrey, W. V., \& Keener, S. (2018). Body-worn cameras and officer perceptions: a mixed-method pretest posttest of patrol officers and supervisors. Journal of Crime and Justice, 1-18. doi:10.1080/0735648X.2018.1479287

Penney, J. W. (2016). Chilling effects: Online surveillance and Wikipedia use. Berkeley Technology \& Law Journal, 31.

Penney, J. W. (2017). Internet surveillance, regulation, and chilling effects online: a comparative case study. Internet Policy Review, 6(2).

Pettit, P. (1989). Consequentialism and Respect for Persons. Ethics, 100(1), 116-126.

Rachels, J. (1975). Why privacy is important. Philosophy \& Public Affairs, 4(4), 323-333.

Ready, J. T., \& Young, J. T. N. (2015). The impact of on-officer video cameras on police-citizen contacts: findings from a controlled experiment in Mesa, AZ. Journal of Experimental Criminology, 11(3), 445458. doi:10.1007/s11292-015-9237-8

Richards, P., Roberts, D., Britton, M., \& Roberts, N. (2017). The exploration of Body-Worn Video to accelerate the decision making skills of Police Officers within an experiential learning environment (Vol. 12).

Rickless, S. C. (2007). The right to privacy unveiled. San Diego Law Review, 44(1), 773-799.

Ryberg, J. (2007). Privacy Rights, Crime Prevention, CCTV, and the Life of Mrs. Aremac. Res Publica, 13(2), 127-143.

Schauer, F. (1978). Fear, Risk and the First Amendment: Unravelling the Chilling Effect. Faculty Publications, 879.

Singer, P. (2009). The Life You Can Save. London: Picador.

Singer, P. (2010). One Atmosphere. In S. M. Gardiner, S. Caney, J. Dale, \& H. Shue (Eds.), Climate Ethics Essential Readings (pp. 181-199). New York: Oxford University Press.

Stalcup, M., \& Hahn, C. (2016). Cops, cameras, and the policing of ethics. Theoretical Criminology, 20(4), 482501. doi:doi:10.1177/1362480616659814

Stanley, J. (2015). Police Body-Mounted Cameras: With Right Policies in Place, a Win For All (v2.0). Retrieved from https://www.aclu.org/other/police-body-mounted-cameras-right-policies-place-winall?redirect=police-body-mounted-cameras-right-policies-place-win-all

Stoycheff, E., Liu, J., Xu, K., \& Wibowo, K. (2019). Privacy and the Panopticon: Online mass surveillance's deterrence and chilling effects. 21(3), 602-619. doi:10.1177/1461444818801317

Thomson, J. J. (1975). The Right to Privacy. Philosophy \& Public Affairs, 4(4), 295-314. doi:10.2307/2265075 
Unger, P. (1996). Living High and Letting Die. Oxford: Oxford University Press.

Wall, E. (2011). Privacy and the Moral Right to Personal Autonomy. International Journal of Applied Philosophy, 25(1), 69-85.

White, M. D., Gaub, J. E., \& Todak, N. (2018). Exploring the Potential for Body-Worn Cameras to Reduce Violence in Police-Citizen Encounters. Policing: A Journal of Policy and Practice, 12(1), 66-76. doi:10.1093/police/paw057

Yokum, D., Ravishankar, A., \& Coppock, A. (2017). Evaluating the Effects of Police Body-Worn Cameras: A Randomized Controlled Trial. Retrieved from Washington DC:

Yokum, D., Ravishankar, A., \& Coppock, A. (2019). A randomized control trial evaluating the effects of police body-worn cameras. 116(21), 10329-10332. doi:10.1073/pnas.1814773116 \%J Proceedings of the National Academy of Sciences

\footnotetext{
' Acknowledgements: I have presented drafts of this paper at a 2018 Roskilde University Moral Philosophy seminar, a 2019 conference on mass state surveillance at Karlsruhe Institut für Technologie, and the 2019 Braga Meetings in Ethics and Political Philosophy. I am grateful for helpful comments on these and other occasions from William Bülow, Matthew Hall, Sean Kaplan, Rune Klingenberg Hansen, Kristian Kragh, Peter Königs, Sune Lægaard, Chris Nathan, Nora Ni Loideain, Kevin Macnish, Ingmar Persson, Scott Robbins, Christian Seidel, Patrick Smith, Thomas Søbirk Petersen, Jørn Sønderholm, Jakob Thrane Mainz, and Anette Zimmerman. I am further grateful for many helpful comments from two anonymous reviewers for the journal and the guest editor of this special issue. Finally, the article owes a great debt above all to Jesper Ryberg, not merely for his invaluable comments on this specific article, but for his style of argument, long exposure to which I suspect has led me to inadvertently (if perhaps not quite successfully) imitate.
} 